\title{
ОСОБЕННОСТИ НЕВРОЛОГИЧЕСКИХ НАРУШЕНИЙ У НЕДОНОШЕННЫХ ДЕТЕЙ В РЕЗИДУАЛЬНОМ ПЕРИОДЕ РАЗВИТИЯ
}

\author{
*Л.Е.Выговская, А.Р.Гайнутдинов \\ Казанская государственная медииинская академия, Казань, Россия
}

Для недоношенных детей характерно нарастание двигательно-рефлекторных и интеллектуальных нарушений с уменьшением срока гестации и увеличением тяжести общего состояния при рождении, что позволяет спрогнозировать вероятность тяжелых инвалидизирующих последствий.

Ключевые слова: недоношенность, срок гестации, двигательные нарушения.

Многочисленными наблюдениями доказано, что недоношенные дети формируют до $50 \%$ долговременной неврологической патологии $[1,4,7]$. Прогноз постнатального развития в значительной мере определяется наличием структурных повреждений головного мозга $[2,3]$. По данным ряда авторов, до $80 \%$ случаев неуспеваемости в школе обусловлены различными состояниями когнитивной недостаточности, включая задержку психического развития, до 20,5\% из них приходится на расстройства мышления, причем только 35\% младших школьников имеют удовлетворительный уровень готовности к обучению в среднеобразовательных школах $[1,4,5]$. Только детальная оценка психомоторного развития позволяет прогнозировать исход перинатальных поражений, а также наметить подходы к разработке эффективных методов лечения и реабилитации недоношенных детей с учётом компенсаторных возможностей головного мозга $[4,6]$.

Цель исследования: проследить развитие недоношенных детей с различными сроками гестации в резидуальном периоде развития, что позволит разграничить варианты нормы от групп риска по задержке психомоторного развития с целью наиболее ранней реабилитации данного контингента пациентов.

Материал и методы исследования: клиническое неврологическое обследование было проведено 413 недоношенным пациентам в возрасте от 7 до 18 лет. В зависимости от степени тяжести общего состояния при рождении дети были подразделены на 2 группы - основную и группу сравнения.

Основную группу составили 222 недоношенных ребенка, родившихся с признаками гипоксии различной степени тяжести, что расценивалось по шкале Апгар, как тяжелое (1-4б.), средней степени тяжести (5-6 б.) и легкой степени тяжести (6-7 б.) состояние. Соответственно гестационному возрасту пациенты были распределены на 4 подгруппы: с I ст. недоношенности (1 подгруппа) наблюдалось 67 (30\%) человек; со II ст. недоношенности (2 подгруппа) - 81 (36,5\%) человек, с III и IV ст. недоношенности (3 и 4 подгруппы) - 52 $(23,4 \%)$ и $22(10 \%)$ пациента соответственно.

Группу сравнения составил 191 пациент. Все дети родились недоношенными без признаков гипоксии. Соответственно гестационному возрасту, пациенты также были распределены на 4 подгруппы: с I ст. недоношенности (1 подгруппа) наблюдались 67 (35\%) человек, со II ст. недоношенности (2 подгруппа) 81 (42,4\%) человек; глубоконедоношенные дети (III и IV подгруппа) составили $52(27,2 \%)$ и $22(11,5 \%)$ ребенка соответственно.

Неврологическая симптоматика оценивалась по следующим проявлениям: особенности двигательно-рефлекторных нарушений, отклонения в интеллектуальном и речевом развитии.

В основной группе пациентов, родившихся с признаками гипоксии, двигательно-рефлекторные нарушения проявлялись следующим образом: для детей с I ст. недоношенности (1 подгруппа) были характерны двигательнорефлекторные нарушения в форме нижней спастической диплегии с преобладанием левосторонних нарушений $(23,9 \%)$ или негрубых пирамидных знаков в конечностях $(35,3 \%)(\mathrm{p}<0,05)$. Пациенты передвигались самостоятельно, без нарушений стато-опорных функций (3 уровень двигательной активнос-

*e-mail: larisa-vigovskaia@rambler.ru 
ти) или дефектной походкой (2 уровень двигательной активности); полностью себя обслуживали, в ряде случаев отмечались негрубые затруднения в мелкой моторике.

Двигательно-рефлекторные нарушения у пациентов со II ст. недоношенности (2 подгруппа) в основной группе носили характер гемипареза $(8,67 \%)$ или нижней спастической диплегии $(11,1 \%)$ с преобладанием правосторонних нарушений на фоне негрубого повышения мышечного тонуса, а также проявлялись в форме спастического тетрапареза с левосторонним преобладанием рефлекторных нарушений - 34,8\% (p<0,05). Дети передвигались самостоятельно дефектной походкой (2 уровень двигательной активности), отмечались затруднения в навыках самообслуживания.

Для глубоконедоношенных пациентов с III IV ст. недоношенности (3 и 4 подгруппы), родившихся в условиях гипоксии, были характерны выраженные двигательно-рефлекторные нарушения в форме атонически - астатического синдрома, либо экстрапирамидный тип пора- жения нервной системы до степени ригидности, дубль-атетоидные гиперкинезы. Стато-опорные функции отсутствовали (0 уровень двигательной активности - 36,6\% и 60,9\% соответственно III и IV ст. недоношенности), либо пациенты передвигались с посторонней помощью (1 уровень двигательной активности - 40,3\% пациентов с III ст. недоношенности), у всех детей наблюдалось грубое ограничение навыков самообслуживания. Характеристика двигательно-рефлекторных нарушений в основной группе пациентов представлена на рис.1.

Для недоношенных больных, родившихся без признаков гипоксии (группа сравнения) были характерны свои особенности (рис.2). У преобладающего числа пациентов с I ст. недоношенности (1 подгруппа) в резидуальном периоде развития отмечались негрубые пирамидные знаки в конечностях (3 уровень двигательной активности - 51,2\%), либо рефлекторные нарушения отсутствовали (4 уровень двигательной активности - 17,5\%) $(\mathrm{p}<0,05)$. Пациенты передвигались самостоятельно без нарушений стато-опорных функций.

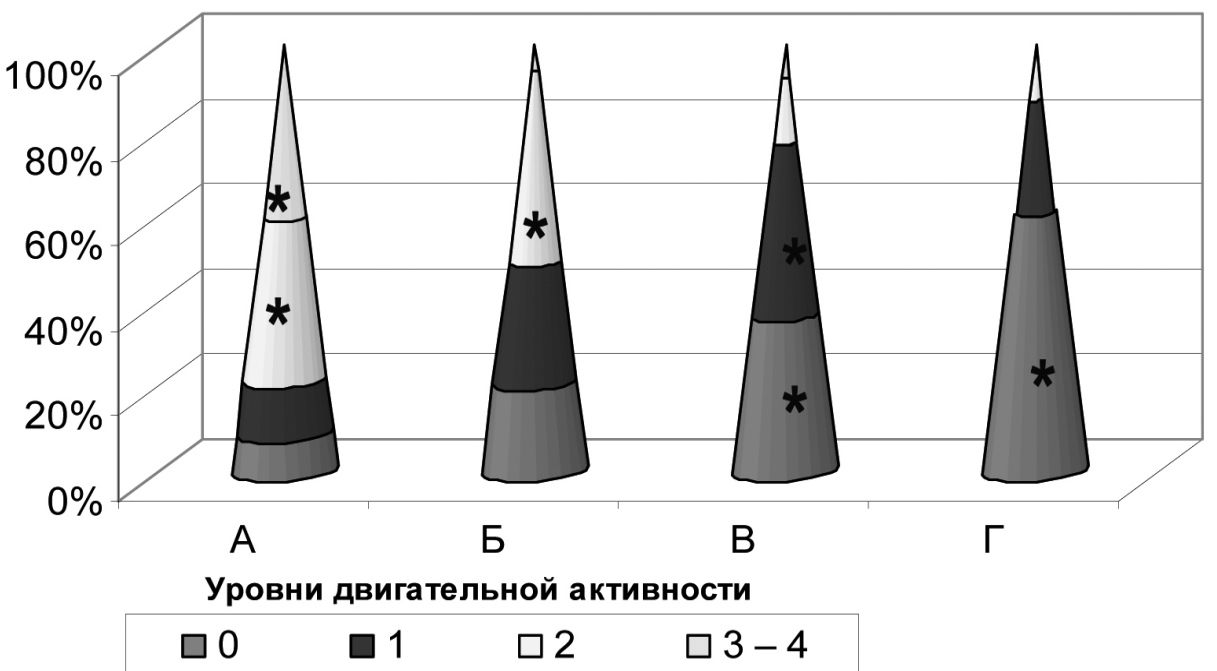

Рис.1. Распределение уровней двигательной активности соответственно срокам гестации у недоношенных больных в резидуальном периоде развития в основной группе (в \%) (А - I степень недоношенности; Б - II степень недоношенности; В III степень недоношенности; Г - IV степень недоношенности; *-p<0,05).
Для пациентов со II и III ст. недоношенности (2 и 3 подгруппы) были характерны нарушения в двигательно - рефлекторной сфере по типу нижнего спастического парапареза и спастического тетрапареза без сторонности преобладания двигательных нарушений (IIІст.), либо с левосторонним преобладанием процесса (IІст.). Пациенты передвигались самостоятельно с нарушением стато-опорных функций (2 уровень двигательной активности - 42\% и 58\% соответственно 2 и 3 подгруппам больных).
У глубоконедоношенных больных с IV ст. недоношенности (4 подгруппа) наблюдались грубые нарушения двигательно-рефлекторной сферы (спастический тетрапарез - 55\% пациентов) с выраженным повышением мышечного тонуса по пирамидному типу, дубль-атетоидными гиперкинезами в конечностях - 11\% больных $(\mathrm{p}<0,05)$ Пациенты передвигались с посторонней помощью (1 уровень двигательной активности). Отмечались ограничения в навыках самообслуживания и нарушения в мелкой моторике. 


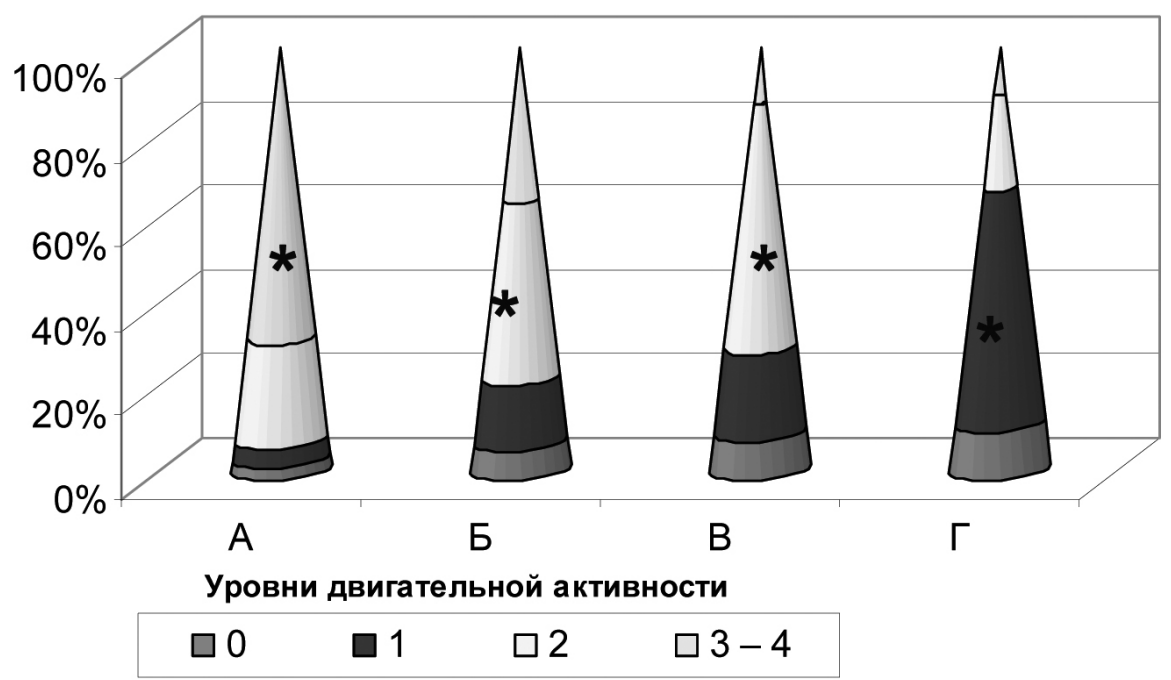

Рис.2. Распределение уровней двигательной активности у недоношенных детей в резидуальном периоде развития в группе сравнения (в \%) (А - I ст. недоношенности; Б - II ст. недоношенности; В - III ст. недоношенности, Г - IV ст. недоношенности; *-р<0,05).
Особенности интеллектуальной сферы в основной группе пациентов имели следующие особенности: для пациентов с I ст. недоношенности основной группы интеллектуальное развитие соответствовало возрастной норме у $52,2 \%$ пациентов $(\mathrm{p}<0,05)$. Негрубое снижение интеллекта отмечалось у подавляющего большинства больных со II ст. недоношенности, родившихся с признаками гипоксии (53\%) $(\mathrm{p}<0,05)$. Пациенты имели преимущественно невербальные формы мышления, а также негрубые и умеренные нарушения в сфере оперативной памяти, анализа и синтеза. Грубое нарушение интеллекта наблюдалось у подавляющего большинства глубоконедоношенных больных - 52\% и 63,6\% соответственно III и IV ст. недоношенности $(\mathrm{p}<0,05)$.

У пациентов группы сравнения интеллектуальные нарушения имели свои особенности. Преобладающее большинство больных с I, II, III ст. недоношенности имели сохранный интеллект - 67\%, 61\%, 61\% соответственно $(\mathrm{p}<0,05)$. Нарушения интеллектуальных функций отмечались у подавляющего большинства пациентов с IV ст. недоношенности - 55\%.

Особенности речевого развития в основной группе больных представлены следующими нарушениями: дислексия отмечалась у $27,3 \% ; 32,7 \%, 20,5 \%$ и $21,7 \%$ человек соответственно четырем подгруппам больных и характеризовалась наличием стойких ошибок слого-словообразования в процессе чтения. У глубоконедоношенных пациентов преобладали афазии-74,6\% (p<0,05). Псевдобульбарная дизартрия наблюдалась у 1,49\% и 3,85\% пациентов в 1 и 3 подгруппах, гиперкинетическая форма дизартрии в несколько раз чаще регистрировалась среди глубоконедоношенных больных (11,5\% и 13,7\% соответственно 3 и 4 подгруппам) Отсутствие фразовой речи чаще отмечалось среди глубоконедоношенных больных (64\% и 78\% соответственно 3 и 4 подгруппам), чем среди пациентов в 1 и 2 подгруппах $(25,4 \%$ и $39 \%)(\mathrm{p}<0,05)$.

В группе сравнения речевые нарушения также имели свои особенности. Нарушения моторных и сенсорных компонентов речи, а также отсутствие фразовой речи преобладали среди пациентов 4 подгруппы (22\%), у остальных категорий недоношенных детей они встречались у $4,5 \%, 12,5 \%$ и 12,8\% пациентов соответственно 3 подгруппам $(\mathrm{p}<0,05)$. Логоневроз наблюдался у 4,3\% пациентов в 3 подгруппе.

\section{Выводы:}

1. Для недоношенных пациентов, родившихся в условиях гипоксии, а также для больных с IV ст. недоношенности, родившихся в удовлетворительном состоянии характерно нарастание двигательно-рефлекторных и интеллектуальных нарушений с уменьшением срока гестации. У недоношенных пациентов с I, II и III ст. недоношенности, родившихся в удовлетворительном состоянии отмечается сохранность двигательно-рефлекторных и интеллектуальных функций, что является оптимизирующим прогностическим признаком в отношении данной категории больных.

2. У глубоконедоношенных пациентов с 
выраженными двигательно-рефлекторными нарушениями в механизмах отсутствия речи может лежать как собственно неполноценность двигательных областей коры, принима-

\section{СПИСОК ЛИТЕРАТУРЫ:}

1. Нейман Е.Г. Профилактика неврологических расстройств у недоношенных детей / Е.Г. Нейман // Вопросы современной педиатрии.-2006.-T.5, № 1.-С.411-412.

2. Тимошенко В.Н. Недоношенные новорожденные дети /В.Н. Тимошенко// - Ростов н/Д, - Красноярск, 2007. - 184c.

3. Скворцов И.А. Развитие нервной системы у детей в норме и патологии /И.А. Скворцов, Н.А. Ермоленко /.- М.: МЕДпресс-информ, 2003. - 246с.

4. Сугак И.А. Перинатальные поражения головного мозга у недоношенных детей: классификация, патогенез, морфологические проявления, исходы / Н.К. Сугак, И.А. Швед, Г.Я. Хулуп, С.К. Клецкий // Медицина.-2003. - № 1.-С.35-37

5. Шпрах В.В. Клинико-нейрофизиологические и ющих участие в артикуляции, так и нарушение связей между первичными корковыми речевыми зонами и двигательными отделами коры, обеспечивающими вокализацию.

нейро-психофизиологические аспекты спастических форм детского церебрального паралича у детей дошкольного и раннего школьного возраста / В.В. Шпрах, С.Ю. Лаврик, А.В. Стародубцев [и др.] // Журнал неврологии и психиатрии им. С.С. Корсакова - 2007. - №10. - С.13-17

6. Chung M.Y. Risk factors for hemodynamically-unrelated cystic periventricular leukomalacia in very low birth weight premature infants / M.Y. Chung, P.C. Fang, C.H. Chung // J. Formos. Med. Assoc.-2005.- № 8.-P.571-577 7. Downie A.L. The impact of periventricular brain injury on reading and spelling abilities in the late elementary and adolescent years / A.L. Downie, V. Frisk, L.S. Jakobson // Neuropsychol. Dev. Cogn. C. Child. Neuropsychol. -2005. -№ 6. - P.479 - 495

\title{
XÜLASə
}

\section{VAXTINDAN ӘVVӘL DOĞULAN KÖRPOLORDӨ İNKISSAFIN REZIDUAL MəRHӘLӘSINNDə NEVROLOJİ POZĞUNLUQLARIN XÜSUSIYYYOTLəRİ}

\author{
L.E.Vıgovskaya, A.R.Gainutdinov \\ Kazan Dövlat Tibb Akademiyası, Kazan, Rusiya
}

Vaxtından əvvəl doğulan körpələr üçün hestasiya müddətinin azalması ilə və doğuş vaxtı ümumi vəziyyətin ağırlı̆̆ının artması ilə hərəki-reflektor və intellektual pozulmaların artması xarakterikdir ki, bu da ağır əlilliyə səbəb olan ağırlaşmaların proqnozunu verməyə imkan verir.

Açar sözlər: vaxtından əvvəl doğum, hamiləlik dövrü, hərəki pozulmalar.

\section{SUMMARY}

\section{FEATURES OF NEUROLOGICAL DISSORDERS İN PREMATURE CHILDREN IN THE RESIDUAL PERIOD OF DEVELOPMENT}

\author{
L.E.Vygovskaya, A.R.Gainutdinov \\ Kazan State Medical Academy, Kazan, Russia
}

Degree of motor - reflex disorders in premature children depends on the severity of the general condition at birth and gestational age. For children characterized by the growth of premature motor-reflex and mental disorders with decreasing gestational age, which allows to predict the probability of severe disabling consequences in the residual period of development.

Key words: prematurity, the period of gestation, motor disturbances.

Redaksiyaya daxil olub: 31.05 .2013

Çapa tövsiyə olunub: 28.06 .2013

Rəyçi: R.K.Şiraliyeva, t.e.d., prof. 